\title{
ERRATUM
}

\author{
S. Nikolaou - M. Hu • N. B. Chilton - D. Hartman •
}

A. J. Nisbet • P. J. A. Presidente - R. B. Gasser

\section{Isolation and characterization of class II myosin genes from Haemonchus contortus}

Published online: 25 March 2006

(C) Springer-Verlag 2006

\section{Parasitol Res (2006) DOI 10.1007/s00436-006-0129-8}

In the online version of this article the name of the first author S. Nikolaou was inadvertently omitted.

The online version of the original article can be found at http://dx. doi.org/10.1007/s00436-006-0129-8

S. Nikolaou · D. Hartman · P. J. A. Presidente

Primary Industries Research Victoria,

475 Mickleham Road,

Attwood, VIC, 3049, Australia

S. Nikolaou $\cdot$ M. Hu $\cdot$ R. B. Gasser $(\bowtie)$

Department of Veterinary Science

The University of Melbourne,

250 Princes Highway,

Werribee, VIC, 3030, Australia

e-mail: robinbg@unimelb.edu.au

Tel.: +61-3-97312000

Fax: +61-3-97312366

R. B. Gasser

Biotechnology Research Institute, Macquarie University,

Sydney, NSW, 2109, Australia

N. B. Chilton

Department of Biology, University of Saskatchewan,

112 Science Place,

Saskatoon, SK, S7N 5EZ, Canada

A. J. Nisbet

Moredun Research Institute, Pentlands Science Park,

Bush Loan, Penicuik,

Midlothian, Scotland, EH26 0PZ, UK 